\title{
A statistical approach for improvement of Best Worst Method (BWM)
}

\author{
Morteza Yazdani $^{1 *}$, Violeta Doval Hernandez ${ }^{2}$, Prasenjit Chatterjee ${ }^{3}$, \\ Edmundas Kazimieras Zavadskas ${ }^{4}$ \\ ${ }^{1}$ Department of Management, Universidad Loyola Andalucia, 41014, Seville, Spain \\ ${ }^{2}$ Alianza por la Solidaridad, Seville, 41003, Spain \\ ${ }^{3}$ Department of Mechanical Engineering, MCKV Institute of Engineering, West Bengal, India \\ ${ }^{4}$ Institute of Sustainable Construction, Vilnius Gediminas Thechnical University, 10223 Vilnius, Lithuania
}

\begin{abstract}
This paper endeavors to measure the consistency of a decision-making tool, popularly known as Best Worst Method (BWM), which is one of the latest developments in multiple-criteria decision analysis (MCDA). BWM is finding a vast arra of applications in the literature. Several investigators have extended this tool. BWM measures the weight of decision-making criterion and is recognized as a subjective decision tool. The first step in this method is to find the best and worst criterion, while we suppose several experts are asked to present their evaluation over set of criteria. The aim is to measure how these judgments are consistent and reliable. So, we statistically (using $\chi 2$ distribution) add a pre-evaluation to experts' opinion and analyze whether the agreement of experts' opinions is satisfactory and group opinion is established. This action improves the quality of the decision-making process by incorporating the reliability evaluation of experts' idea. This extension for BWM helps decision makers in facilitating and getting results that are more consistent for criteria evaluation. We present examples in sustainable construction and architecture project.
\end{abstract}

Keywords: Best Worst Method, group decision, consistecny, multi criteria decision analysis.

\section{Introduction}

Improving and extending decision-making tools is very popular among the academic community and researchers. Range of studies have been conducted to show the quality of decision-making increases when the consistency improves. This issue in multi attribute decision making is highlighted since decades. The fundamental complexity in many decision making condition is the theme of consistency and reliability (Leung \& Cao, 2000). One method that was under investigation many times is analytical hierarchy procees (AHP) (Alonso \& Lamata, 2006; Xu, 2000; Aguarón, Escobar, \& Moreno-Jiménez, 2016). Like AHP which is a subjective decision making tool, (Rezaei, 2015) invented a new algorithm that operates based on a linear programing model. The method is named Best Worst Method (BWM) and practically due to its effective nature ereceived too much attentions in many fields and disciplines (Gupta \& Barua, 2016; Rezaei, Nispeling, Sarkis, \& Tavasszy, 2016; Rezaei, Wang, \& Tavasszy, 2015; Ahmadi, Kusi-Sarpong, \& Rezaei, 2017).

Recently Zolfani, Yazdani, and Zavadskas (2018) worked on an extended version of stepwise weight assessment ratio analysis method. The authors used a statistical technique in order to test whether the experts agree on their judgments. The approach confirms the consistency of the method and allows decision makers go forward and rely on the results. In this paper we are going to apply the recent approach for BWM in order to check its usability and performance. Second section presents the algorithm, then an example about evaluating sustainable building factors are provided and a conclusion ends the debate.

\section{Improved BWM method}

Best Worst Method (BWM) is one of the efficient and recent born MCDA tool. Decision makers usually utilize it for determining the subjective weight of criterion. The method has captured many attentions in various applications as

\footnotetext{
*Corresponding author. E-mail: myazdani@uloyola.es
} 
supplier selection, energy resources and air transportation quality. BWM is used to produce the importance of decision criteria based on expert (decision makers, respondents) attitude and in the classical version of BWM method there is no mechanism to test expert's attitude consistency. We suppose several experts are willing to present their judgment on some factors. How then all these judgments can be trustable and reliable is the question of this paper. In other words, we try to figure out how the results of aggregated opinions are consistent. The experts) are asked to evaluate each criterion based on their cognition, experience and knowledge and to rank them in order of their preferences (from best to worst). Then, we follow the following steps:

Step 1: Calculation of the average criterion values $\bar{t}_{j}$ :

$$
\bar{t}_{j}=\frac{\sum_{k=1}^{t} t_{j k}}{r},
$$

where $t_{j k}$ indicates the ranking of the $j^{\text {th }}$ criteria by the $k^{\text {th }}$ respondent and $r$ is the number of respondents.

Step 2: Calculation of criteria weights $\left(q_{j}\right)$.

The criteria weights are calculated by dividing the average value of each criterion by the sum of the criteria priority (rank) values $\left(t_{j}\right)$ :

$$
q_{j}=\frac{\bar{t}_{j}}{\sum_{j=1}^{n} t_{j}} .
$$

The total criteria weight must be equal to one, signifying $\sum_{j=1}^{n} q_{j}=1$ and $t_{j}$ is the criteria priority values.

Step 3: Verifying the reliability of the expert opinions.

Step 3-1: Now, for the purpose of verifying the reliability of the expert opinions, dispersion in criteria ranking as given by the experts is first computed using Eq. (3), followed by the calculation of the variation of the obtained values using Eq. (4). Dispersion basically indicates the measurement of the variation between the multiple expert opinions.

$$
\begin{gathered}
\sigma^{2}=\frac{1}{r-1} \sum_{k=1}^{n}\left(t_{j k}-\bar{t}_{j}\right)^{2} \\
\beta_{j}=\frac{\sigma}{\bar{t}_{j}}
\end{gathered}
$$

Step 3-2: Determination of coefficient of concordance (agreement) for the experts' opinions: Determine the coefficient of concordance $(W)$ of the experts or the respondents (eleven for the illustrative case study) opinions to express the reliability of individual expert opinion using Eq. (5).

$$
\begin{gathered}
W=\frac{12 S}{r^{2}\left(n^{3}-n\right)-r \sum_{k=1}^{r} T_{k}} . \\
W \in[0,1],
\end{gathered}
$$

where $S$ is the total square deviation of the rankings of each criterion, expressed by Eq. (6).

$$
S=\sum_{j=1}^{n}\left[\sum_{k=1}^{r} t_{j k}-\frac{1}{n} \sum_{j=1}^{n} \sum_{k=1}^{r} t_{j k}\right]^{2} .
$$

In this equation, $T_{k}$ the index of reiterated ranks in the $r$ rank, $r$ is the number of respondents and $n$ is the number of criteria. However, as the calculated $W$ value is stochastic; thus, significance of the concordance coefficient should be estimated. Kendall (1970) indicated that when $n$ is greater than 7, a distribution with the degrees of freedom $v=n-1$ should be considered by the experts or the respondents (eleven for the illustrative case study).

Step 3-3: Calculation of $\chi^{2}$ :

$$
\chi_{\alpha, v}^{2}=W . r .(n-1)
$$

Step 3-4: Testing the $\chi^{2}>\chi_{\text {table }}^{2}$. It has been proved that if the calculated $\chi^{2}$ value is greater than the critical tabular value $\chi_{\text {table }}^{2}$ for the pre-selected level of significance, then the hypothesis about the agreement of independent experts 
'judgments' is not rejected. If $\chi^{2}>\chi_{\text {table }}^{2}$ the significance of concordance coefficient exists on $\alpha$ level, then the agreement of experts 'opinions is satisfactory and group opinion is established. In this case, the tabular value $\left(\chi_{\text {table }}^{2}\right)$ was taken from Fisher and Yates statistical tables (Fisher \& Yates, 1963). Once the agreement among expert opinion is achieved, then the mains steps for BWM is denoted:

Step 4: The decision maker (DM) determines a Set of decision criteria: $\left\{c_{1}, c_{2}, \ldots, c_{n}\right\}$.

Step 5: The DM chooses the best and the worst criteria. In this step, the DM chooses the best and the worst criteria among the set of identified criteria in last step. The best criterion represents the most desirable or the most significant one while the worst criterion is the least important one among others.

Step 6: The DM conducts pairwise comparisons between the best criterion and the other criteria. In this step, the goal is to identify the preference of the most important criterion to the other criteria. DM uses a scale from 1 to 9 (1: equally important, and 9: extremely more important). The comparison outcome is described as Best-to other vector: $A_{B}=\left(a_{B 1}, a_{B 2}, \ldots, a_{B n}\right)$. Where $a_{B j}$ represents the preference of the best criterion B over the criterion $\mathrm{j}$ and $a_{B B}=1$

Step 7: The DM conducts pairwise comparison between the other criteria and the worst criterion. Same as last step, the comparison results are expressed by Other-to-worst vector: $A_{W}=\left(a_{1 W}, a_{2 W}, \ldots, a_{n B}\right)^{T}$. Where $a_{j w}$ represents the preference of the best criterion $\mathrm{j}$ over the criterion $\mathrm{W}$ and $a_{W W}=1$

Step 8: Calculating the optimal weights: $\left(W_{1}^{*}, W_{2}^{*}, \ldots, W_{n}^{*}\right)$, For more information of this method, refer to (Rezaei, 2015).

\section{An example of the proposed technique}

In this section, an empirical example of evaluating factors in a sustainable building has been presented in order to establish the appropriateness of the adopted statistical approach for measuring the consistency of BWM. As the table shows, Eleven experts participated in this research considering these elements: Technical factors $\left(\mathrm{C}_{1}\right)$, waste disposal system $\left(\mathrm{C}_{2}\right)$, Environmental factors $\left(\mathrm{C}_{3}\right)$, Total costs of project $\left(\mathrm{C}_{4}\right)$, Safety and security factors $\left(\mathrm{C}_{5}\right)$, green or sustainable materials $\left(\mathrm{C}_{6}\right)$ and energy consumption control $\left(\mathrm{C}_{7}\right)$. The experts were demanded to rate each factor from 1 to 7 . In case of BWM method, suppose each expert provides worst and best criterion. For example, Expert 1 considers $\mathrm{C}_{3}$ as best option, and then he/she compares other criteria to that (for example $\mathrm{C}_{1} 6$ times greater than $\mathrm{C}_{3}$ ). We call this table (Table 1) efficiency rank of attributes. The next step is to find the attribute weights using Eq. (2). As seen in Table 2, all the computation are observed.

Table 1. Expert primary judgment over seven factors (Attribute efficiency)

\begin{tabular}{|c|c|c|c|c|c|c|c|c|}
\hline \multicolumn{1}{|c|}{ Experts } & $\mathrm{C}_{1}$ & $\mathrm{C}_{2}$ & $\mathrm{C}_{3}$ & $\mathrm{C}_{4}$ & $\mathrm{C}_{5}$ & $\mathrm{C}_{6}$ & $\mathrm{C}_{7}$ & \\
\hline 1 & 6 & 2 & 1 & 3 & 4 & 5 & 7 & \\
\hline 2 & 6 & 1 & 3 & 2 & 5 & 4 & 7 & \\
\hline 3 & 5 & 1 & 2 & 4 & 3 & 7 & 6 & \\
\hline 4 & 7 & 2 & 1 & 4 & 3 & 6 & 5 & \\
\hline 5 & 6 & 1 & 3 & 4 & 2 & 7 & 5 & \\
\hline 6 & 4 & 2 & 3 & 5 & 1 & 7 & 6 & \\
\hline 7 & 5 & 1 & 2 & 3 & 4 & 6 & 7 & \\
\hline 8 & 5 & 1 & 3 & 4 & 2 & 7 & 6 & \\
\hline 9 & 5 & 1 & 2 & 4 & 3 & 7 & 6 & \\
\hline 10 & 4 & 3 & 1 & 5 & 2 & 7 & 6 & \\
\hline 11 & 5 & 1 & 2 & 4 & 3 & 7 & 6 & \\
\hline & $\mathbf{5 8}$ & $\mathbf{1 6}$ & $\mathbf{2 3}$ & $\mathbf{4 2}$ & $\mathbf{3 2}$ & $\mathbf{7 0}$ & $\mathbf{6 7}$ & Total = 308, Av =44 \\
\hline Sum & 5.27 & 1.45 & 2.09 & 3.82 & 2.91 & 6.36 & 6.09 & \\
\hline Average (Equation 1) & 5 & 1 & 2 & 4 & 3 & 7 & 6 & \\
\hline Attribute Priorities & 0.188 & 0.052 & 0.075 & 0.136 & 0.104 & 0.227 & 0.218 & \\
\hline $\begin{array}{l}\text { Attribute weights } \\
\text { (Equation 2) }\end{array}$ & & & & & & & \\
\hline
\end{tabular}


While the value of $\chi_{\text {table }}^{2}$ (Table in appendix), for $(\mathrm{v}=6)$ and importance level of $1 \%$ is equal to 16.81 . Then, because 54 is bigger than 16.81, the results are consistent and acceptable. Therefore, the experts can continue to compute the rest of the process.

The weights are appeared in Table 3 and consistency 0.19 shows to what extent the results are reliable.

Table 2. Expert primary judgment over seven factors

\begin{tabular}{|c|c|c|c|c|c|c|c|}
\hline \multirow{2}{*}{ Process of computation } & \multicolumn{7}{|c|}{ Efficiency attributes $x i ; j=1,2, \ldots$} \\
\hline & $\mathrm{C}_{1}$ & $\mathrm{C}_{2}$ & $\mathrm{C}_{3}$ & $\mathrm{C}_{4}$ & $\mathrm{C}_{5}$ & $\mathrm{C}_{6}$ & $\mathrm{C}_{7}$ \\
\hline Sum of ranks & 58 & 16 & 23 & 42 & 32 & 70 & 67 \\
\hline The average attribute rank value & 5.273 & 1.455 & 2.091 & 3.818 & 2.909 & 6.364 & 6.091 \\
\hline Attribute rank & 5 & 1 & 2 & 4 & 3 & 7 & 6 \\
\hline Attribute weight & 0.188 & 0.052 & 0.075 & 0.136 & 0.104 & 0.227 & 0.218 \\
\hline $\operatorname{Sum} \sum_{k=1}^{n}\left(t_{j k}-\bar{t}_{j}\right)^{2}$ & 8.18 & 4.73 & 6.91 & 7.64 & 12.91 & 10.55 & 4.91 \\
\hline Dispersion of expert $\sigma^{2}$ & 0.82 & 0.47 & 0.69 & 0.76 & 1.29 & 1.05 & 0.49 \\
\hline Variation $\quad \beta_{j}=\frac{\sigma}{\bar{t}_{j}}$ & 0.172 & 0.473 & 0.398 & 0.229 & 0.391 & 0.161 & 0.115 \\
\hline Ranking sum average & \multicolumn{7}{|c|}{44} \\
\hline The total square ranking deviation & \multicolumn{7}{|c|}{$\mathrm{S}=2774$} \\
\hline The coefficient of concordance $(\mathbf{W})$ & \multicolumn{7}{|c|}{$\mathrm{W}=\mathbf{0 . 8 2}$} \\
\hline \multicolumn{8}{|l|}{$\begin{array}{l}\text { The significance of the concordance coefficient } \\
\text { (no related ranks) }\end{array}$} \\
\hline \\
\hline$\frac{1}{n-1} \sum_{k=1}^{r} T_{k}=0$ & \multicolumn{7}{|c|}{$\chi_{\alpha, v}^{2}=\frac{12 * 2774}{11 * 7(8)}=54$} \\
\hline $\begin{array}{l}\text { Rank of table concordance }\left(\chi_{\text {table }}^{2}\right) \text { when the importance } \\
\text { equal to } 1 \% \text {. }\end{array}$ & \multicolumn{7}{|c|}{ The freedom degrees value of a solved problem, $v=n-1=6$} \\
\hline Compatibility of expert judgement $\chi_{\alpha, v}^{2}=54>\chi_{\text {table }}^{2}$ & \multicolumn{7}{|c|}{$\begin{array}{l}\text { - The hypothesis about the consent of experts in rankings is } \\
\text { accepted }\end{array}$} \\
\hline
\end{tabular}

Table 3. The weights of BWM

\begin{tabular}{|l|c|c|c|c|c|c|c|}
\hline Factors & $\begin{array}{c}\text { technical } \\
\text { factors }\end{array}$ & $\begin{array}{c}\text { waste } \\
\text { disposal }\end{array}$ & $\begin{array}{c}\text { Env. } \\
\text { Factors }\end{array}$ & $\begin{array}{c}\text { total } \\
\text { cost }\end{array}$ & $\begin{array}{c}\text { safety \& } \\
\text { security }\end{array}$ & $\begin{array}{c}\text { green } \\
\text { materials }\end{array}$ & $\begin{array}{c}\text { energy } \\
\text { control }\end{array}$ \\
\hline Weights & 0.0859 & $\mathbf{0 . 3 2 3 9}$ & 0.1718 & 0.1718 & 0.1288 & 0.0442 & 0.0736 \\
\hline
\end{tabular}

\section{Conclusions}

In this paper, an improved version of the original BWM method has been proposed. It has been shown that adding an extra statistical algorithm at the beginning of the calculation of BWM is essential in order to check the accuracy of group decision makers. This strategy might be useful in other subjective criteria estimation tools like Decision making trial and evaluation laboratory (DEMATEL), Entropy, criteria importance through inter criteria correlation (CRITIC) methods etc.

\section{Acknowledgements}

The authors are thankful of being invited for this communication and another thanks to reviewers. 


\section{References}

Aguarón, J., Escobar, M. T., \& Moreno-Jiménez, J. M. (2016). The precise consistency consensus matrix in a local AHP-group decision making context. Annals of Operations Research, 245(1-2), 245-259. https://doi.org/10.1007/s10479-014-1576-8

Ahmadi, H. B., Kusi-Sarpong, S., \& Rezaei, J. (2017). Assessing the social sustainability of supply chains using Best Worst Method. Resources, Conservation and Recycling, 126, 99-106. https://doi.org/10.1016/j.resconrec.2017.07.020

Alonso, J. A., \& Lamata, M. T. (2006). Consistency in the analytic hierarchy process: a new approach. International Journal of Uncertainty, Fuzziness and Knowledge-Based Systems, 14, 445-459. https://doi.org/10.1142/S0218488506004114

Fisher, R. A., \& Yates, F. (1963). Statistical tables for biological, agricultural and medical research (6 ${ }^{\text {th }}$ ed.). London: Oliver and Boyd.

Gupta, H., \& Barua, M. K. (2016). Identifying enablers of technological innovation for Indian MSMEs using best-worst multi criteria decision making method. Technological Forecasting and Social Change, 107, 69-79. https://doi.org/10.1016/j.techfore.2016.03.028

Kendall, M. G. (1970). Rank correlation methods (4 ${ }^{\text {th }}$ ed.). Griffin, London.

Leung, L. C., \& Cao, D. (2000). On consistency and ranking of alternatives in fuzzy AHP. European Journal of Operational Research, 124, 102-113. https://doi.org/10.1016/S0377-2217(99)00118-6

Rezaei, J. (2015). Best-worst multi-criteria decision-making method. Omega, 53, 49-57. https://doi.org/10.1016/j.omega.2014.11.009

Rezaei, J., Nispeling, T., Sarkis, J., \& Tavasszy, L. (2016). A supplier selection life cycle approach integrating traditional and environmental criteria using the best worst method. Journal of Cleaner Production, 135, 577-588. https://doi.org/10.1016/j.jclepro.2016.06.125

Rezaei, J., Wang, J., \& Tavasszy, L. (2015). Linking supplier development to supplier segmentation using Best Worst Method. Expert Systems with Applications, 42(23), 9152-9164. https://doi.org/10.1016/j.eswa.2015.07.073

$\mathrm{Xu}, \mathrm{Z}$. (2000). On consistency of the weighted geometric mean complex judgement matrix in AHP. European Journal of Operational Research, 126(3), 683-687. https://doi.org/10.1016/S0377-2217(99)00082-X

Zolfani, S. H., Yazdani, M., \& Zavadskas, E. K. (2018). An extended stepwise weight assessment ratio analysis (SWARA) method for improving criteria prioritization process. Soft Computing, 22(22), 7399-7405. https://doi.org/10.1007/s00500-018-3092-2 
Yazdani, M.; Doval Hernandez, V.; Chatterjee, P.; Zavadskas, E. K. 2019.

A statistical approach for improvement of Best Worst Method (BWM)

\section{Appendix}

\begin{tabular}{|c|c|c|c|c|c|c|}
\hline \multirow[b]{2}{*}{$v$} & \multicolumn{6}{|c|}{$\alpha$} \\
\hline & 0.100 & 0.050 & 0.025 & 0.010 & 0.005 & 0.001 \\
\hline 1 & 2.7055 & 3.8415 & 5.0239 & 6.6349 & 7.8794 & 10.8276 \\
\hline 2 & 4.6052 & 5.9915 & 7.3778 & 9.2103 & 10.5966 & 13.8155 \\
\hline 3 & 6.2514 & 7.8147 & 9.3484 & 11.3449 & 12.8382 & 16.2662 \\
\hline 4 & 7.7794 & 9.4877 & 11.1433 & 13.2767 & 14.8603 & 18.4668 \\
\hline 5 & 9.2364 & 11.0705 & 12.8325 & 15.0863 & 16.7496 & 20.5150 \\
\hline 6 & 10.6446 & 12.5916 & 14.4494 & 16.8119 & 18.5476 & 22.4577 \\
\hline 7 & 12.0170 & 14.0671 & 16.0128 & 18.4753 & 20.2777 & 24.3219 \\
\hline 8 & 13.3616 & 15.5073 & 17.5345 & 20.0902 & 21.9550 & 26.1245 \\
\hline 9 & 14.6837 & 16.9190 & 19.0228 & 21.6660 & 23.5894 & 27.8772 \\
\hline 10 & 15.9872 & 18.3070 & 20.4832 & 23.2093 & 25.1882 & 29.5883 \\
\hline 11 & 17.2750 & 19.6751 & 21.9200 & 24.7250 & 26.7568 & 31.2641 \\
\hline 12 & 18.5493 & 21.0261 & 23.3367 & 26.2170 & 28.2995 & 32.9095 \\
\hline 13 & 19.8119 & 22.3620 & 24.7356 & 27.6882 & 29.8195 & 34.5282 \\
\hline 14 & 21.0641 & 23.6848 & 26.1189 & 29.1412 & 31.3193 & 36.1233 \\
\hline 15 & 22.3071 & 24.9958 & 27.4884 & 30.5779 & 32.8013 & 37.6973 \\
\hline 16 & 23.5418 & 26.2962 & 28.8454 & 31.9999 & 34.2672 & 39.2524 \\
\hline 17 & 24.7690 & 27.5871 & 30.1910 & 33.4087 & 35.7185 & 40.7902 \\
\hline 18 & 25.9894 & 28.8693 & 31.5264 & 34.8053 & 37.1565 & 42.3124 \\
\hline 19 & 27.2036 & 30.1435 & 32.8523 & 36.1909 & 38.5823 & 43.8202 \\
\hline 20 & 28.4120 & 31.4104 & 34.1696 & 37.5662 & 39.9968 & 45.3147 \\
\hline 21 & 29.6151 & 32.6706 & 35.4789 & 38.9322 & 41.4011 & 46.7970 \\
\hline 22 & 30.8133 & 33.9244 & 36.7807 & 40.2894 & 42.7957 & 48.2679 \\
\hline 23 & 32.0069 & 35.1725 & 38.0756 & 41.6384 & 44.1813 & 49.7282 \\
\hline 24 & 33.1962 & 36.4150 & 39.3641 & 42.9798 & 45.5585 & 51.1786 \\
\hline 25 & 34.3816 & 37.6525 & 40.6465 & 44.3141 & 46.9279 & 52.6197 \\
\hline 26 & 35.5632 & 38.8851 & 41.9232 & 45.6417 & 48.2899 & 54.0520 \\
\hline 27 & 36.7412 & 40.1133 & 43.1945 & 46.9629 & 49.6449 & 55.4760 \\
\hline 28 & 37.9159 & 41.3371 & 44.4608 & 48.2782 & 50.9934 & 56.8923 \\
\hline 29 & 39.0875 & 42.5570 & 45.7223 & 49.5879 & 52.3356 & 58.3012 \\
\hline 30 & 40.2560 & 43.7730 & 46.9792 & 50.8922 & 53.6720 & 59.7031 \\
\hline 31 & 41.4217 & 44.9853 & 48.2319 & 52.1914 & 55.0027 & 61.0983 \\
\hline 63 & 77.7454 & 82.5287 & 86.8296 & 92.0100 & 95.6493 & 103.4424 \\
\hline 127 & 147.8048 & 154.3015 & 160.0858 & 166.9874 & 171.7961 & 181.9930 \\
\hline 255 & 284.3359 & 293.2478 & 301.1250 & 310.4574 & 316.9194 & 330.5197 \\
\hline 511 & 552.3739 & 564.6961 & 575.5298 & 588.2978 & 597.0978 & 615.5149 \\
\hline 1023 & 1081.3794 & 1098.5208 & 1113.5334 & 1131.1587 & 1143.2653 & 1168.4972 \\
\hline
\end{tabular}

